\title{
Cutibacterium avidum resists surgical skin antisepsis in the groin-a potential risk factor for periprosthetic joint infection: a quality control study
}

Steven M. Maurer ${ }^{1} \mathbb{D}$, Laura Kursawe ${ }^{4}$, Stefan Rahm³ ${ }^{3}$, Julia Prinz ${ }^{1,5}$, Annelies S. Zinkernagel ${ }^{1}$, Annette Moter ${ }^{4}$, Stefan P. Kuster ${ }^{1}$, Reinhard Zbinden ${ }^{2}$, Patrick O. Zingg ${ }^{3}$ and Yvonne Achermann ${ }^{1^{*}}$

\begin{abstract}
Background: The skin commensal Cutibacterium avidum has been recognized as an emerging pathogen for periprosthetic joint infections (PJI). One currently assumes that the early occurring PJls are a consequence of skin commensals contaminating the peri-implant tissue during surgery. We addressed whether standard skin antisepsis with povidone-iodine/alcohol before total hip arthroplasty (THA) is effective to eliminate colonizing bacteria with focus on C. avidum.
\end{abstract}

Methods: In a single-center, prospective study, we screened all patients for skin colonizing C. avidum in the groin before THA. Only in the patients positive for C. avidum, we preoperatively repeated skin swabs after the first and third skin antisepsis and antibiotic prophylaxis. We also obtained dermis biopsies for microbiology and fluorescence in situ hybridization (FISH).

Results: Fifty-one out of 60 patients (85\%) were colonized on the skin with various bacteria, in particular with C. avidum in 12 out of 60 . Skin antisepsis eliminated C. avidum in eight of ten (20\%) colonized patients undergoing THA. Deeper skin (dermis) biopsies were all culture negative, but FISH detected single positive ribosome-rich C. avidum in one case near sweat glands.

Conclusion: Standard skin antisepsis was not effective to completely eliminate colonizing C. avidum on the skin in the groin of patients undergoing THA. Colonizing with C. avidum might pose an increased risk for PJI when considering a THA. Novel more effective antisepsis strategies are needed.

Trial registration No clinical trial

Keywords: Cutibacterium avidum, Cutibacterium species, Skin antisepsis, Periprosthetic joint infection, Hip

${ }^{*}$ Correspondence: yvonne.achermann@usz.ch

${ }^{1}$ Division of Infectious Diseases and Hospital Epidemiology, University Hospital Zurich, University of Zurich, Zurich, Switzerland

Full list of author information is available at the end of the article

\section{Background}

Absolute numbers of periprosthetic joint infections (PJI) are increasing due to the increasing aging population with the need of joint prostheses [1]. Most commonly isolated microorganisms are staphylococci, streptococci, enterococci, gram-negative bacteria, and facultative anaerobic bacteria such as Cutibacterium species (mainly Cutibacterium acnes and Cutibacterium original author(s) and the source, provide a link to the Creative Commons licence, and indicate if changes were made. The images or other third party material in this article are included in the article's Creative Commons licence, unless indicated otherwise in a credit line to the material. If material is not included in the article's Creative Commons licence and your intended use is not permitted by statutory regulation or exceeds the permitted use, you will need to obtain permission directly from the copyright holder. To view a copy of this licence, visit http://creativecommons.org/licenses/by/4.0/. The Creative Commons Public Domain Dedication waiver (http://creativeco mmons.org/publicdomain/zero/1.0/) applies to the data made available in this article, unless otherwise stated in a credit line to the data. 
avidum [formerly Propionibacterium acnes and avidum, respectively]) [2]. These bacteria cause infections, which are difficult to treat because they hide in a self-made biofilm consisting of an extracellular matrix of polymeric substances [3]. Notably, most of the currently available antibiotics are not active against bacteria in biofilms due to the bacterial persistence and tolerance $[4,5]$. Treatment of PJI requires aggressive surgical debridement with prolonged usage of antibiotics or even the exchange of the whole prosthesis [2]. Most of the PJI occur when viable bacteria on the skin surface or dermis contaminate deeper tissue layers and eventually the arthroplasty at the time of surgery [6-8]. Therefore, pre- or intraoperative prevention strategies are key to avoid intraoperative bacterial contamination. Prevention strategies are multifaceted with the focus on perioperative antibiotic prophylaxis within 30-60 minutes before surgery and on skin antisepsis immediately before surgical incision of the skin $[7,9,10]$. Various skin antisepsis agents are in use, among others povidone-iodine (PVI), chlorhexidine gluconate (CHG), or alcohol [7], which target the natural inhabitants of the human skin $[11,12]$.

C. avidum was recently identified as an emerging pathogen in hip arthroplasty infections [13-15]. In a prospective study, we found that $32.3 \%$ of all patients undergoing hip arthroplasty surgery were colonized with $C$. avidum in the groin region, which is rich of sweat glands [16]. Obesity with more sweating was a predisposing factor for colonization in those patients [16] and thus the likely explanation for the increasing number of $C$. avidum PJI in our center [17]. Cutibacterium species are also found in deeper skin, near sebaceous or sweat glands. This propensity may render them more resistant to antiseptic agents. Therefore, we investigated if the standard skin antisepsis we use in our clinic eliminates efficiently all $C$. avidum skin colonization at time of surgical incision by swab cultures of superficial and deeper skin structures as well as by FISH in the dermis.

\section{Methods \\ Study design and patient population}

In a single-center prospective study at the University Hospital Balgrist in Zurich, Switzerland, we screened patients 8-14 days prior to hip surgery for C. avidum colonization and tested the intraoperative effect of skin antisepsis on C. avidum. We included all patients with a planned primary THA surgery through a direct anterior approach, i.e. between musculus tensor fascia latae and musculus sartorius [18] from October 2018 until April 2019. Basic clinical characteristics, i.e. age, sex, BMI, type of operation of the patients were retrieved from the charts. In the patients screened positive for C. avidum, we intraoperatively searched for viable bacteria of superficial and deeper skin structures using routine culture techniques and FISH after triple skin antisepsis.

In every patient antibiotic prophylaxis with singledose cefuroxim $(1.5 \mathrm{~g}$ in patients $<80 \mathrm{~kg}$ and $3 \mathrm{~g}$ in patients $\geq 80 \mathrm{~kg}$ ) was administered $30-60 \mathrm{~min}$ prior to THA. No additional preoperative decolonization or antiseptic showering was performed on the day before surgery.

\section{Skin antisepsis, skin swab and dermis biopsies}

For antisepsis we used Betaseptic ${ }^{\circledR}$ solution (Mundipharma, Limburg, Germany) which contains 3.24 g povidone-iodine, $38.9 \mathrm{~g}$ 2-propanol and $38.9 \mathrm{~g}$ ethanol $96 \%$ in $100 \mathrm{ml}$ solution according to the manufacturer. If the patient had an allergy against iodine, antisepsis was performed with Kodan ${ }^{\circledR}$ (Schülke, Norderstedt, Germany), which is a 2-propanol/1-propanol/biphenyl-2-ol solution containing $45.9 \mathrm{~g}$ 2-Propanol, $10.0 \mathrm{~g}$ 1-Propanol, $0.20 \mathrm{~g}$ Biphenyl-2-ol, 30\% hydrogen peroxide and purified water in $100 \mathrm{ml}$ solution, according to the manufacturer. Surgical antisepsis was performed 3 times for one minute with a one-minute interval in between. Due to the time required for collection of skin scrapings after first and third antisepsis, total duration of the antisepsis procedure was up to $5 \mathrm{~min}$ before incision of the skin. The sterile blades were changed after the first and second scraping procedure to prevent cross-contamination.

Skin swabs were taken by scraping over the skin in the groin near the planned anterior incision with the same sterile blade 4 to 5 times. The skin material on the blade was collected with eSwabs (Copan, Brescia, Italy).

Immediately after surgical skin incision for THA implantation, one biopsy from the dermis at the edge of surgical anterior incision was obtained $(5 \mathrm{~cm}$ in length, $0.3-0.5 \mathrm{~cm}$ in width and $0.5 \mathrm{~cm}$ in depth) and cut into two pieces, one was used for evaluation of bacterial species and one for FISH.

\section{Microbiological analysis of skin swabs and dermis biopsies} eSwabs and dermis biopsies were analyzed for bacterial growth at the Institute of Medical Microbiology of the University of Zurich. For aerobe cultivation, swabs were streaked out onto Columbia sheep blood agar without antibiotics (bioMérieux; Mary-l'Etoile, France) and onto colistin-nalidixic acid blood agar (bioMérieux). A Brucella agar plate (in-house 10\% sheep blood agar [Becton Dickinson] with hemin and vitamin K1 [Sigma-Aldrich Merck]) was inoculated for anaerobe cultivation. All aerobic plates were incubated for 7 days at $37{ }^{\circ} \mathrm{C}$. The anaerobe environment was ensured with GEN bags (bioMérieux). Focusing on anaerobe growing bacteria, skin swabs after skin antisepsis were solely anaerobically 
incubated on Brucella agar plates for 10 days at $37{ }^{\circ} \mathrm{C}$. Skin biopsies were processed in the same way as skin swabs except an additional thioglycolate broth (bioMérieux) was incubated for 10 days and a MacConkey-Agar (bioMérieux), a Chocolate agar PolyViteX (bioMérieux) and a PEA agar plate (bioMérieux) were incubated for 2 days. All bacteria were identified by matrix-assisted laser desorption ionization (MALDI-TOF) using a Bruker MALDI Biotyper (Becton Dickinson). We used the three-phase streaking pattern for a semiquantitative analysis for C. avidum in all skin swab samples. We defined low level of bacteria when growth was observed in the first section $(+)$, medium level when growth in the second section $(++)$, and high level when growth in the third and last section $(+++)$.

\section{Visualization of bacteria of dermis biopsies with FISH}

To visualize the presence of bacteria below the skin surface in the dermis, we performed FISH of intraoperatively acquired biopsies at the Biofilm center in Berlin, Germany. To immediately fix the dermis samples in the operating theatre, we used a FISH-fixation solution, optimized for the detection of a wide variety of microorganisms including gram-positive, gram-negative bacteria and fungi (FISHopt ${ }^{\circledR}$, MoKi Analytics Germany) [19].

$2 \mu \mathrm{m}$ sections of approximately $1 \mathrm{~cm}$ dermis samples were prepared and analyzed by FISH as previously described $[20,21]$. Briefly, the fixed samples were embedded in cold polymerizing resin Technovit 8100 (Kulzer, Wehrheim, Germany) according to the manufacture's manual and cut in $2 \mu \mathrm{m}$ thick sections. Cross sections of ten dermis biopsies were embedded and sectioned including epidermis, dermis and subcutaneous tissue per section. At least four sections per sample were analyzed using FISH. For the hybridization process, a preheated hybridization buffer was added to the sample which contained fluorescently labeled probes corresponding to the target rRNA. The whole tissue sections were analyzed microscopically by two independent investigators for approximately 45 min each.

We used the pan-bacterial probe (EUB338) and the specific FISH probe (PAC) [22-24], which manly targets C. acnes but shows also $100 \%$ homology to closely related Cutibacterium modestum (formerly C.utibacterium humerusii), which was originally identified from a joint infection [25], Cutibacterium namnetense, Acidithiobacillus thiooxidans, Mycobacterium chitae (Silva Database, 24. November. 2020, selection, Additional file 1: Table S3). To visualize $C$. avidum, we designed and evaluated a specific probe (PRAV) (Table 1, Additional file 1: Table S2, Figure S1, Figure S2). In silico evaluation of the FISH probe PRAV was accomplished using the software probeCheck (http://131.130.66.200/cgi-bin/ probecheck/content.pl?id=home), which revealed $100 \%$
Table 1. Probes used for fluorescence in situ hybridization in dermal biopsies

\begin{tabular}{llll}
\hline Probe & Target & Specificity & References \\
\hline EUB338 & 16S rRNA & Most bacteria & Amann [48] \\
PAC & 16S rRNA & $\begin{array}{l}\text { Cutibacterium acnes } \\
\text { Cutibacterium modestum }\end{array}$ & Poppert [23] \\
& & Cutibacterium namnetense \\
& & Acidothiobacterium thiooxidans \\
*PRAV & Mycobacterium chitae & \\
& \multicolumn{4}{c}{$\begin{array}{l}\text { Cutibacterium avidum } \\
\text { Acidipropionibacterium acidipropionici } \\
\end{array}$} & $\begin{array}{l}\text { Acidipropionibacterium propionicum } \\
\text { Acidipropionibacterium jensenii }\end{array}$ & \\
& & Acidipropionibacterium theonii & \\
& &
\end{tabular}

*Further information regarding the sequences in the Additional file 1: Table S2

homology with C. avidum and four closely related species Acidipropionibacterium (formerly Propionibacterium) acidipropionici, Acidipropionibacterium (formerly Propionibacterium) propionicum, Acidipropionibacterium (formerly Propionibacterium) jensenii, and Acidipropionibacterium (formerly Propionibacterium) thoenii [26] (Additional file 1: Table S2). Except for C. avidum, these species have no clinical relevance in PJI. Sensitivity and specificity of the probe PRAV was confirmed using fixed cultures of C. avidum MM433 (clinical isolate), $C$. avidum strain (clinical isolate of this study), and C. acnes MM1127 (clinical isolate) as described in the supplement (Additional file 1: Table S4). Identity of all strains was confirmed by $16 \mathrm{~S}$ rRNA-gene sequencing using TPU1 and RTU3 primers as previously describted [27]. Amplicons were sequenced using a commercial sequencing facility (Microsynth AG, Switzerland) and compared to all currently available sequences from the public databases (EMBL and GenBank) and the curated centroid database of the program SmartGene (SmartGene Inc., Switzerland) [28]. In addition, a tissue biopsy of the pseudocapsule of a proven PJI with positive growth of C. avi$d u m$ was used as a positive control.

The nucleic acid stain 4',6-diamidino-2-phenylindole (DAPI) was applied to all samples to visualize microorganisms and cell host nuclei. Microscopic evaluation was performed using an epifluorescence microscope (AxioImager z1, Carl Zeiss, Germany) with narrow band filter sets Cy3, Cy5 and FITC (AHF Analysentechnik, Germany). Digital images were taken using the ZEN software delivered with the instrument.

\section{Statistical methods}

Descriptive statistics were performed using Excel version 16.41. The binominal confidence limits in Fig. 2 were calculated using Stata version 14.2 (StataCorp) . Futher 


\section{Colonizing bacteria in the groin before antisepsis in $\%(n=60)$}

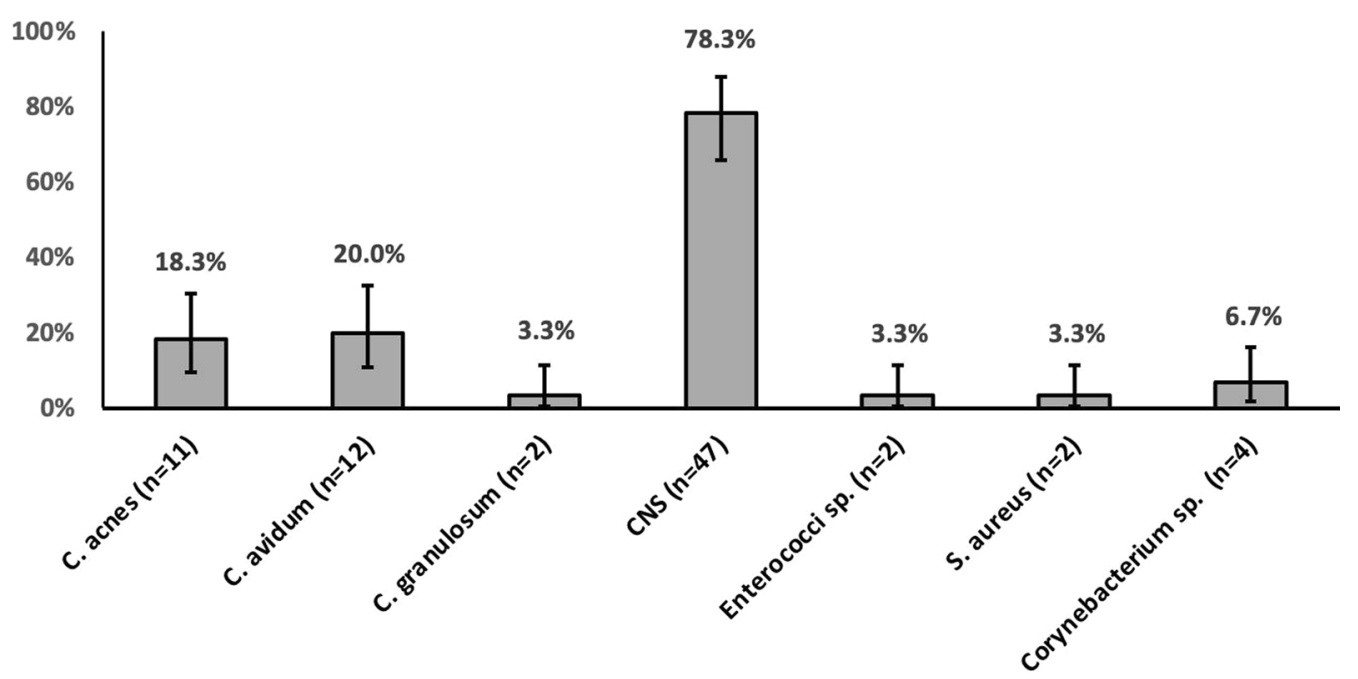

Fig. 1 Percentage (with binomial confidence limits) of skin colonizing bacteria in the groin before antiseptic treatment. C. acnes, Cutibacterium acnes; C. avidum, Cutibacterium avidum; C. granulosum, Cutibacterium granulosum; CNS, coagulase-negative staphylococci; S. aureus, Staphylococcus aureus; Corynebacterium sp. included C. tuberculostearicum, C. glucuronolyticum, C. singular, and C. accolens; Enterococci sp. included one E. faecalis and one E. faecium. CNS included S. epidermidis in $n=29(48.3 \%)$, S. hominis in $n=22(36.7 \%)$, S. capitis in $n=8(13.3 \%)$, S. haemolyticus in $n=6$ $(10 \%)$, S. warneri in $n=3(5 \%)$, S. pettenkoferi in $n=2(3.3 \%)$, S. lugdunensis in $n=2(3.3 \%)$, S. simulans in $n=1(1.7 \%)$

statistics were not performed due to a small number of patients.

\section{Results}

From October 2018 to April 2019, we enrolled 60 patients prior to THA in our study. Approximately half of the patients $(46.7 \%$; 28$)$ were female with a median age of 67 (range, $40-87$ years). The median BMI of all patients was $26.7 \mathrm{~kg} / \mathrm{m}^{2}$ (range, 19.1-39.1), whereof the 12 patients with positive $C$. avidum colonization had a higher BMI with a median of $32.1 \mathrm{~kg} / \mathrm{m}^{2}$ (range, $21.8-$ 39.1). Almost all patients (98.3\%) underwent primary THA with an anterior approach due to osteoarthritis, except for one patient, who required the operation due to femoral head necrosis. In 55\% (33 of 60) of patients, THA was performed on the left hip (Additional file 1: Table S1).

Only 12 of 60 (20\%) patients were colonized with $C$. avidum while most of the patients were colonized with other bacteria such as coagulase-negative staphylococci (CNS) (47, 78.3\%), C. acnes (11, 18.3\%), Corynebacterium sp. (4, 6.7\%), Cutibacterium granulosum (2, 3.3\%), Enterococci sp. (2, 3.3\%), S. aureus (2, 3.3\%) (Fig. 1, Additional file 1: Table S1). Ten out of 12 patients colonized with $C$. avidum were intraoperatively tested for persistent bacterial growth after routine skin antisepsis and perioperative antibiotic prophylaxis. Two $C$. avidum-positive patients were excluded due to change of operation date. We found viable bacteria in eight of ten $(80 \%)$ after the first and in five of ten (50\%) patients after the third round of antisepsis. Focusing on absolute $C$. avidum growth rate, antisepsis was ineffective in four of ten $(40 \%)$ after the first and two of ten (20\%) after the third antisepsis. The semiquantitative analysis of C. avidum before and after antisepsis generally shows low amount of bacterial growth (Table 2). In contrast, dermis biopsies were in all cases culture negative.

FISH was applied in all ten culture-negative dermis biopsies. FISH is a molecular technique with fluorescently labeled oligonucleotide probes which target in our case specifically ribosomes. Ribosomes are highly abundant in actively replicating bacterial cells. The FISH signal intensity correlates with the ribosomal content and therefore can be used as activity marker [29-32]. However, since the ribosome content may vary between bacteria, the absence of a FISH signal cannot differentiate between a dead or resting state. To counterstain all bacteria, also the ones not detected by FISH, we used the nucleic acid specific stain DAPI, which detects host cell nuclei as well as microorganisms.

In all samples, few single bacteria were detected by nucleic acid stain DAPI only, whereas EUB338, PRAV and PAC probe were negative. These single bacteria are visualized according to size and morphology and frequently located in the subcutaneous fat tissue. In one 
case, we detected FISH positive bacteria, indicating ribosome-rich and therefore presumably active bacteria [29-32]. Using the specific C. avidum/ A. acidipropionici/ A. propionicum/ A. jensenii/ A. thoeni- probe, we did not find any FISH-positive bacteria in the lumen of the sweat glands. However, we did find bacteria positive with the PRAV probe close to structures compatible with sweat glands, located at the interface between dermis and subcutaneous fat tissue (Fig. 2). One positive control with culture C. avidum positivity (pseudocapsule tissue biopsy from an infected arthroplasty with $C$. avidum) was analyzed for comparison with the dermis of uninfected cases and revealed a higher number of bacteria. Among DAPIpositive cells single FISH-positive bacteria were detected by the EUB3338 and PRAV probe (Fig. 3).

\section{Discussion}

Prevention of PJI is key to avoid re-operations and prolonged antibiotic treatment after arthroplasty surgery [33]. One of the current prevention strategies is immediate skin antisepsis before surgery in conjunction with single dose antibiotic prophylaxis 30-60 minutes prior to surgery to eliminate viable bacteria on the skin, which we also used in this study. C. avidum is a natural inhabitant of the human skin in particular in obese patients $[10,11]$ and recently recognized as a relevant pathogen in hip PJIs [7-9]. In our study of 60 patients, $12(20 \%)$ were colonized with $C$. avidum prior to hip surgery. Preoperative skin antisepsis eliminated C. avidum in $80 \%$ of patients. In fact, we found viable C. avidum in $20 \%$ of the patients on the skin surface, which might be a risk factor for intraoperative colonization of the joint prosthesis and thus for developing a PJI. We strictly followed the required exposure time of antiseptics given by the manufacturer specifications (one minute exposure time before major interventions) and by the in-house guidelines of a minimum of three antiseptical rounds. This may not be enough when implanting foreign material.

This is the first study revealing the insufficient antisepsis of C. avidum on the skin. Other studies focusing on different microorganisms and different skin antisepsis strategies show similar results $[8,34,35]$. In a randomized trial, Patrick et al. showed that skin antisepsis with sequential application of PVI and CHG reduced the bacterial numbers in the surgical wound more effectively than PVI alone in patients undergoing spinal surgery [8]. Blonna et al. found similar results focusing on coagulasenegative staphylococci and C. acnes [35]. For C. acnes, a recent randomized study revealed a higher reduction of C. acnes after skin preparation with topical benzoyl peroxide than with chlorhexidine [36]. Heckmann et al. evaluated whether higher concentrations of chlorhexidine with an additional mechanical scrub would be more effective in eliminating growth of $C$. acnes than standard antisepsis [37]. No significant difference was found leading to the conclusion that also mechanical scrub cannot eradicate $C$. acnes in deeper layers of the skin. Further studies are needed to improve antisepsis strategies of the skin prior to surgery with focus on reaching the dermis including the subepidermal glands for completely killing any viable bacteria on the skin at time of surgery. For that, an innovative approach could be the application of photodynamic therapy (PDT) [34, 38-41] to reduce colonizing bacteria. In a recent study we showed a $100 \%$ reduction of viable bacteria after skin antisepsis and PDT with methyl aminolevulinate (MAL) [34]. The treatment, however, led to transient skin erythema which is an obstacle for immediate surgery. PDT is certainly very promising but the optimal parameters with the ideal balance of bactericidal effect versus skin irritation have to be investigated.

In one patient, we visualized bacteria at the border of the subcutaneous fat tissue indicating a possible niche for bacteria protected from skin antisepsis and thus a potential source for contamination of deep peri-implant tissue at time of surgical incision and implantation of the hip prosthesis. A recent study reported the presence of bacteria in deep tissues, which were considered as sterile areas [42], leading to the assumption that not only the superficial skin bacteria but also bacteria in the dermis may find the way to deeper structures and infect an implant. Lee et al. found viable $C$. acnes-another skin commensalin the dermal tissue in 7 out of 10 male volunteers after surface skin antisepsis [43]. Remaining bacteria in dermal glands can be a source of inoculation of deeper structures by surgical incision [44]. There is an increasing number of studies describing $C$. acnes remaining in dermis despite skin antisepsis $[45,46]$. However, we found no viable bacteria in the dermis with routine tissue culture methods. No other study than ours exists so far focusing on C. avidum persistance on skin surface and/or in deeper structures after surgical antisepsis. In our study, the FISH-results showed, that in most of the cases, only a few single bacteria per section were detected, mostly in the subcutis stained by DAPI, but the FISH probes showed no signal, which indicate a rather resting or inactive state. Only in one case, DAPI-positive bacteria were also tested FISH-positive indicating ribsosome-rich and presumably viable $C$. avidum. The low numbers of FISH-positive bacteria, however, could be influenced by the routine single antibiotic prophylaxis 30-60 min before the start of the surgery aiming bactericidal antibiotic concentration in the operating field. 
Table 2 Bacterial growth results after skin antisepsis of 10 patients colonized with C. avidum at time of hip arthroplasty surgery

\begin{tabular}{|c|c|c|c|}
\hline \multirow[t]{2}{*}{ Patient-Nr. } & \multirow{2}{*}{$\begin{array}{l}\text { Preoperative skin swabs (outpatient clinic) } \\
\text { within } 1-2 \text { weeks before surgery }\end{array}$} & \multicolumn{2}{|c|}{ Perioperative skin swabs } \\
\hline & & After first antisepsis & After third antisepsis \\
\hline \multirow[t]{2}{*}{4} & C. avidum (+) & No growth & No growth \\
\hline & S. epidermidis & & \\
\hline 17 & C. avidum (+) & C. avidum (+) & C. avidum (+) \\
\hline \multirow[t]{5}{*}{23} & C. granulosum & No growth & C. granulosum \\
\hline & C. avidum (++) & & \\
\hline & S. epidermidis & & \\
\hline & S. haemolyticus & & \\
\hline & S. epidermidis & & \\
\hline \multirow[t]{4}{*}{24} & C. avidum $(++)$ & C. avidum (+) & No growth \\
\hline & S. epidermidis & S. epidermidis & \\
\hline & C.acnes & C.acnes & \\
\hline & & C. granulosum & \\
\hline \multirow[t]{3}{*}{32} & C. avidum (+) & S. capitis & No growth \\
\hline & S. epidermidis & & \\
\hline & S. hominis & & \\
\hline \multirow[t]{5}{*}{34} & C. avidum (+) & C.acnes & No growth \\
\hline & S. epidermidis & & \\
\hline & Staphylococcus lugdunensis & & \\
\hline & Staphylococcus capitis & & \\
\hline & Corynebacterium tuberculostearicum & & \\
\hline 43 & C. avidum (+) & $\begin{array}{l}\text { S. epidermidis } \\
\text { S. hominis } \\
\text { S. haemolyticus } \\
\text { S. capitis }\end{array}$ & S. epidermidis \\
\hline 45 & $\begin{array}{l}\text { C. avidum (+) } \\
\text { Enterococcus faecalis } \\
\text { Enterococcus facium } \\
\text { S. epidermidis }\end{array}$ & C. avidum (+) & No growth \\
\hline 51 & $\begin{array}{l}\text { C. avidum (+) } \\
\text { S. epidermidis }\end{array}$ & C. avidum $(++)$ & $\begin{array}{l}\text { C. avidum (+) } \\
\text { S. epidermidis }\end{array}$ \\
\hline 53 & $\begin{array}{l}\text { S. epidermidis } \\
\text { C. avidum (+) } \\
\text { S. lugdunensis }\end{array}$ & $\begin{array}{l}\text { S. epidermidis } \\
\text { C. acnes } \\
\text { S. hominis }\end{array}$ & S. epidermidis \\
\hline
\end{tabular}

We used the three-phase streaking pattern for a semiquantitative analysis for $C$. avidum in all skin eSwab samples. We defined low level of bacteria when growth in the first section $(+)$, medium when growth in the second section $(++)$, and high when growth in the third and last section $(+++)$

A limitation of our study is the intraoperative focus on C. avidum and not on other colonizing bacteria, which resulted in evaluating the skin antisepsis effect in a low number of patients. Another limitation is the fact that we did not inhibit the antiseptics and possibly transferred traces into the eSwabs during the scraping of the skin. This might have caused inhibition and an underestimation of the actual bacterial growth. Since we focused

(See figure on next page.)

Fig. 2 FISH of a dermis biopsy shows single C. avidum cells located close to structures compatible with sweat glands, located at the border of the dermis to the subcutaneous fat tissue. The tissue section was hybridized with the panbacterial probe EUB338 ${ }_{\mathrm{Cy} 5}$ (mangenta), the $C$. acnes/ $C$.

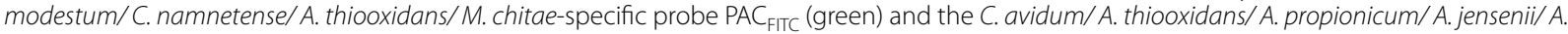
thoeni-specific probe PRAV ${ }_{\mathrm{Cy} 3}$ (orange). Nucleic acids were stained with DAPI. a Overview of the biopsy, overlay of all fluorescence channels and background fluorescence allows orientation within the tissue (b). At higher magnification of the inset marked in (a), single rods are located at the border of the dermis and the subcutaneous fat tissue. $\mathbf{c}$ Inset of (b) showed the detected rods at higher magnification (d to $\mathbf{g}$ ), the identical microscopic field as (c) with separate fluorescence channels, DAPI, Cy3, Cy5, and FITC, respectively. Note the detected rod was positive in DAPI (c), the PRAV (d), and EUB338 (e) probe, but showed no signal with PAC (f) 

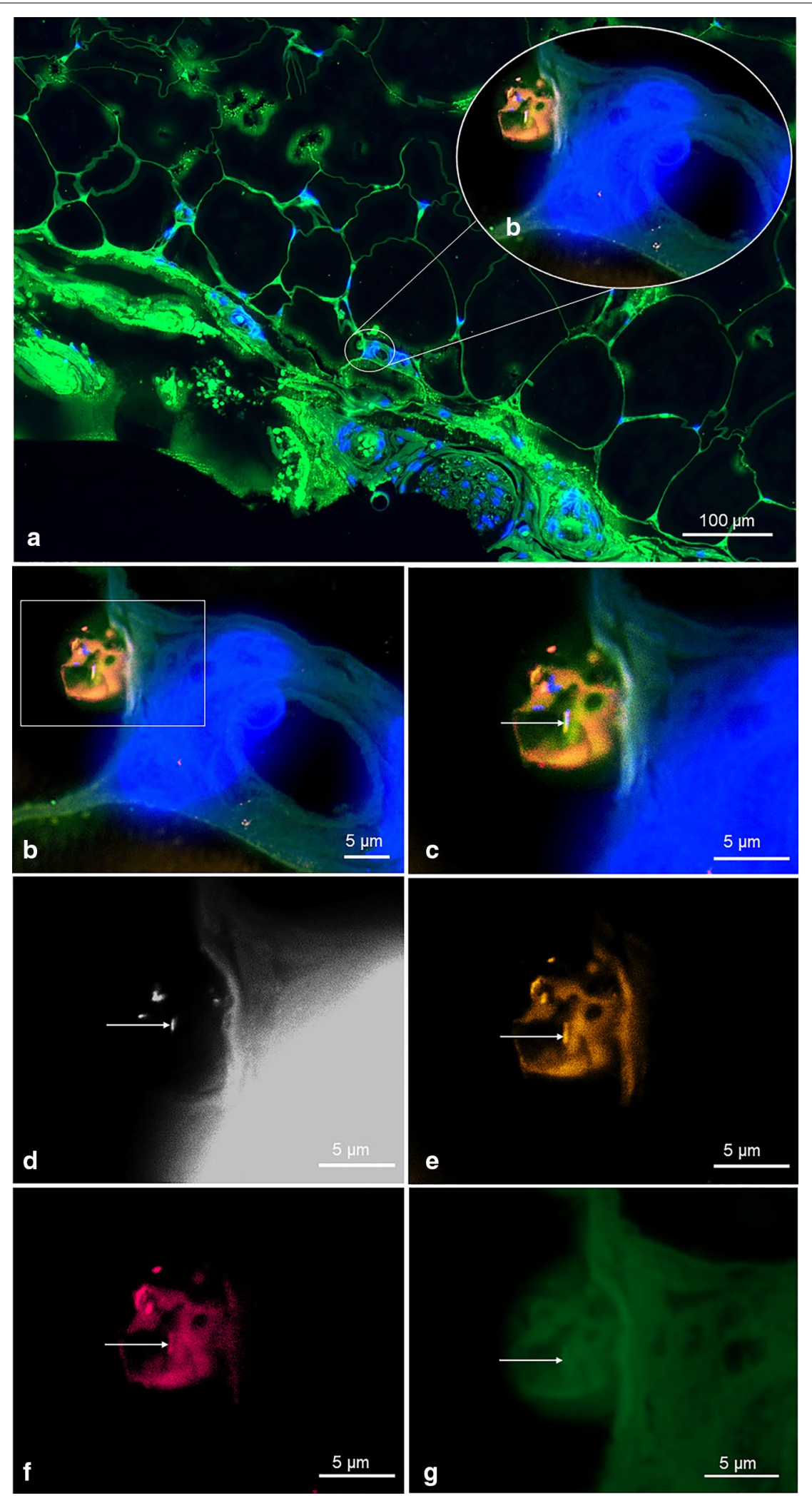

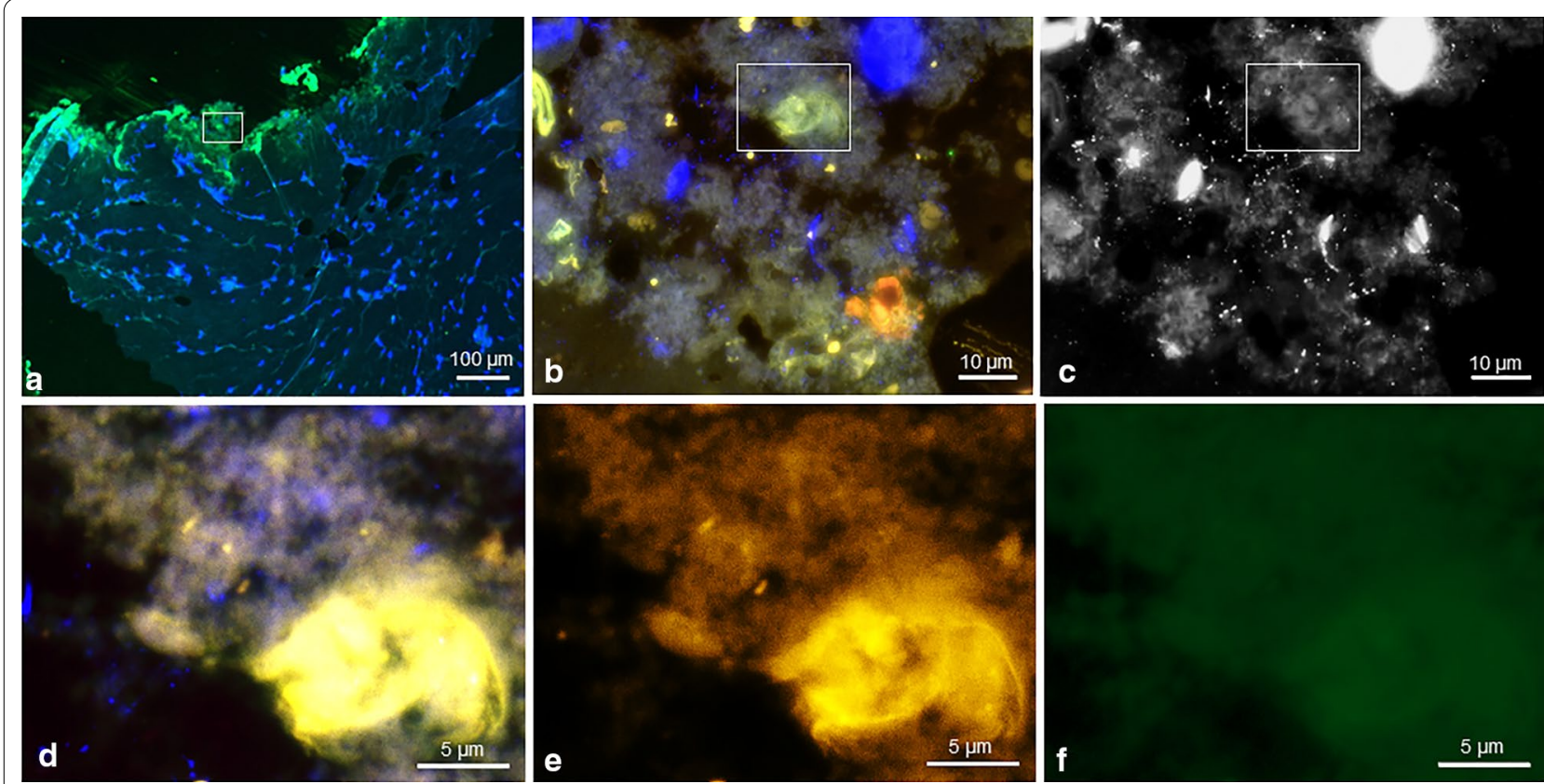

Fig. 3 FISH of a C. avidum culture positive tissue (capsule tissue) biopsy fixed during surgery, shows single C. avidum cells in the tissue. The tissue section was hybridized with the panbacterial probe EUB338 ${ }_{\mathrm{Cy} 5}$ (mangenta), the C. acnes/C. modestum/C. namnetense-specific probe PAC $C_{\mathrm{FITC}}$ (green) and the C. avium/ A. thiooxidans, A. propionicum, A. jensenii, A. thoeni-specific probe PRAV $\mathrm{Cyz}_{3}$ (orange). Nucleic acids were stained with DAPI. a Overview of the biopsy, overlay of all fluorescence channels and background fluorescence shows the destruction of the tissue, also visible at higher magnification of the inset (b) marked in (a). c The identical microscopic field in the DAPI channel only (black and white) shows multiple DAPI-positive pleomorphic microorganisms scattered in the tissue. $\mathbf{d}$ Inset of (c) at higher magnification single rods are visualized in the tissue. $\mathbf{e}$ Some rods stained positive with PRAV in the Cy3 channel but no signal was detected with the PAC in the FITC channel (f)

on C. avidum, which has a prolonged cultivation time, screening for skin colonization had to be completed 7-14 days before surgery and may be different than a screening performed on the day of surgery.

\section{Conclusion}

Standard skin antisepsis with povidone-iodine/alcohol in combination with antibiotic prophylaxis incompletely eliminates C. avidum from the groin area at time of surgical incision of the skin. With the one positive C. avidum FISH result, we can only illuminate but not prove our hypothesis that $C$. avidum in the dermis might be a potential source for infecting prostheses perioperatively. The clinical significance of our study is to highlight the orthopedic surgeon's diligence regarding the treatment of wound margins with care, especially when implanting prosthetic material, since we showed that the skin antisepsis is not efficient in eliminating all colonizing bacteria. Future studies are needed to find skin antisepsis with more potency or other antisepsis methods reaching the deeper tissue of the dermis.

\section{Supplementary Information}

The online version contains supplementary material available at https:/doi. org/10.1186/s13756-021-00883-1.
Additional file 1. Supplement.

\section{Abbreviations}

PJl: Periprosthetic joint infections; THA: Total hip arthroplasty; FISH: Fluorescence in situ hybridization; PVI: Alcoholic povidone-iodine; CHG: Chlorhexidine gluconate; CNS: Coagulase-negative staphylococci.

\section{Acknowledgements}

We thank the study nurse Christa Fritschi for the study support, Susanne Blasowitsch for the microbiological support at the Institution of Microbiology of the University of Zurich, Alicia Oberländer for technical assistance, Bianka Bartik for the administration of the project at the University Hospital Balgrist, Scott Babin and Roberto Speck for proofreading the manuscript.

\section{Author contributions}

SM was a major contributor in the acquisition of the data, analyzing it and writing the manuscript. LK and AM both preformed the FISH-Analysis and therefore contributors in the acqusition of the data and also contributed to the review and editing of the manuscript. SK was a contributor in conceptualization, analysis oft he data. SK and JP were involved in reviewing and editing of the manuscript. SR and PZ were both contributors investigation and methodology of the study. They were also involved in reviewing and editing of the manuscript. AZ was a contributor in interpretation of the date and was also involved in editing and reviewing of the manuscript. RZ was a contributor in supervision of the labratory and methodology, as well as reviewing and editing of the manuscript. YA was a major contributor in conceptualization, supervision, funding and resource acquisition, and a major contributor in writing of the manuscript. All authors read and approved the final manuscript. 


\section{Funding}

This work was supported by the "Swiss Life Jubiläumsstiftung" and by the Clinical Research Priority Program of the University of Zurich for the CRPP "Precision medicine for bacterial infections".

\section{Availability of date and materials}

All data generated or analysed during this study are included in this published article and its supplementary information files.

\section{Ethics approval and consent to participate}

The study has been approved on 18 June 2018 by the cantonal ethic committee of Zurich, Switzerland (BASEC-Nr: 2018-00783), and all patients signed a study-specific informed consent.

\section{Consent for publication}

\section{Not applicable.}

\section{Competing interests}

The authors declare that they have no competing interests.

\section{Author details}

${ }^{1}$ Division of Infectious Diseases and Hospital Epidemiology, University Hospital Zurich, University of Zurich, Zurich, Switzerland. ${ }^{2}$ Institute of Medical Microbiology, University of Zurich, Zurich, Switzerland. ${ }^{3}$ Department of Orthopedics, University Hospital Balgrist, Zurich, Switzerland. ${ }^{4}$ Institute of Microbiology, Infectious Diseases and Immunology, Charité-Universitätsmedizin Berlin Berlin, Germany. ${ }^{5}$ Department of Dermatology, University Hospital Zurich, University of Zurich, Zurich, Switzerland.

Received: 28 March 2020 Accepted: 5 January 2021

Published online: 01 February 2021

\section{References}

1. Del Pozo JL, Patel R. Clinical practice. Infection associated with prosthetic joints. N Engl J Med. 2009;361(8):787-94.

2. Tande AJ, Patel R. Prosthetic joint infection. Clin Microbiol Rev. 2014;27(2):302-45.

3. Arciola CR, Campoccia D, Montanaro L. Implant infections: adhesion, biofilm formation and immune evasion. Nat Rev Microbiol. 2018;16(7):397-409.

4. Hoiby N, Ciofu O, Johansen HK, Song ZJ, Moser C, Jensen PO, et al. The clinical impact of bacterial biofilms. Int J Oral Sci. 2011;3(2):55-65.

5. Yan J, Bassler BL. Surviving as a community: antibiotic tolerance and persistence in bacterial biofilms. Cell Host Microbe. 2019;26(1):15-21.

6. Pulido L, Ghanem E, Joshi A, Purtill JJ, Parvizi J. Periprosthetic joint infection: the incidence, timing, and predisposing factors. Clin Orthop Relat Res. 2008;466(7):1710-5.

7. Dumville JC, McFarlane E, Edwards P, Lipp A, Holmes A, Liu Z. Preoperative skin antiseptics for preventing surgical wound infections after clean surgery. Cochrane Database Syst Rev. 2015;4:003949.

8. Patrick S, McDowell A, Lee A, Frau A, Martin U, Gardner E, et al. Antisepsis of the skin before spinal surgery with povidone iodine-alcohol followed by chlorhexidine gluconate-alcohol versus povidone iodine-alcohol applied twice for the prevention of contamination of the wound by bacteria: a randomised controlled trial. Bone Joint J. 2017;99(10):1354-65.

9. Bratzler DW, Dellinger EP, Olsen KM, Perl TM, Auwaerter PG, Bolon MK, et al. Clinical practice guidelines for antimicrobial prophylaxis in surgery. Surg Infect (Larchmt). 2013;14(1):73-156.

10. Berrios-Torres SI, Umscheid CA, Bratzler DW, Leas B, Stone EC, Kelz RR, et al. Centers for disease control and prevention guideline for the prevention of surgical site infection, 2017. JAMA Surg. 2017;152(8):784-91.

11. McGinley KJ, Webster GF, Leyden JJ. Regional variations of cutaneous propionibacteria. Appl Environ Microbiol. 1978;35(1):62-6.

12. Corvec S. Clinical and biological features of Cutibacterium (formerly Propionibacterium) avidum, an underrecognized microorganism. Clin Microbiol Rev. 2018;31(3):e00064-e117.
13. Achermann Y, Liu J, Zbinden R, Zingg PO, Anagnostopoulos A, Barnard E, et al. Propionibacterium avidum: a virulent pathogen causing hip periprosthetic joint infection. Clin Infect Dis. 2018;66(1):54-63.

14. Wildeman P, Bruggemann H, Scholz CF, Leimbach A, Soderquist B. Propionibacterium avidum as an etiological agent of prosthetic hip joint infection. PLOS ONE. 2016;11(6):e0158164.

15. Zeller VA, Letembet VA, Meyssonnier VA, Heym B, Ziza JM, Marmor SD. Cutibacterium (Formerly Propionibacterium) avidum: a rare but avid agent of prosthetic hip infection. J Arthroplasty. 2018;33(7):2246-50.

16. Boni L, Kuster SP, Bartik B, Zbinden R, Zingg PO, Achermann Y. Association of Cutibacterium avidum colonization in the groin with obesity: a potential risk factor for hip periprosthetic joint infection. Clin Infect Dis. 2018;67(12):1878-82

17. von Ruesten A, Steffen A, Floegel A, van der AD, Masala G, Tjonneland A , et al. Trend in obesity prevalence in European adult cohort populations during follow-up since 1996 and their predictions to 2015. PLoS ONE. 2011;6(11):27455

18. Smith-Petersen MN. A new supra-articular subperiosteal approach to the hip joint. Am J Orthop Surg. 1917;s2-15(8):592-5.

19. Gescher DM, Mallmann C, Kovacevic D, Schmiedel D, Borges AC, Schweickert B, et al. A view on Bartonella quintana endocarditis-confirming the molecular diagnosis by specific fluorescence in situ hybridization. Diagn Microbiol Infect Dis. 2008;60(1):99-103.

20. Mallmann C, Siemoneit S, Schmiedel D, Petrich A, Gescher DM, Halle $E$, et al. Fluorescence in situ hybridization to improve the diagnosis of endocarditis: a pilot study. Clin Microbiol Infect. 2010;16(6):767-73.

21. Moter A, Leist G, Rudolph R, Schrank K, Choi BK, Wagner M, et al. Fluorescence in situ hybridization shows spatial distribution of as yet uncultured treponemes in biopsies from digital dermatitis lesions. Microbiology. 1998;144(9):2459-67.

22. Amann RIBB, Olson RJ, Chisholm SW, Devereux R, Stahl DA. Combination of 165 rRNA-targeted oligonucleotide probes with flow cytometry for analyzing mixed microbial populations. Appl Environ Microbiol. 1990;56(6):1919-25.

23. Poppert S, Riecker M, Essig A. Rapid identification of Propionibacterium acnes from blood cultures by fluorescence in situ hybridization. Diagn Microbiol Infect Dis. 2010;66(2):214-6.

24. Wallner G, Amann R, Beisker W. Optimizing fluorescent in situ hybridization with rRNA-targeted oligonucleotide probes for flow cytometric identification of microorganisms. Cytometry. 1993;14(2):136-43.

25. Butler-Wu SM, Sengupta DJ, Kittichotirat W, Matsen FA 3rd, Bumgarner RE. Genome sequence of a novel species, Propionibacterium humerusii. J Bacteriol. 2011;193(14):3678.

26. Scholz CF, Kilian M. The natural history of cutaneous propionibacteria, and reclassification of selected species within the genus Propionibacterium to the proposed novel genera Acidipropionibacterium gen. nov., Cutibacterium gen. nov. and Pseudopropionibacterium gen. nov. Int J Syst Evolut Microbiol. 2016;66(11):4422-32.

27. Moter A, Hoenig C, Choi BK, Riep B, Göbel UB. Molecular epidemiology of oral treponemes associated with periodontal disease. J Clin Microbiol. 1998;36(5):1399-403.

28. Chatellier S, Mugnier N, Allard F, Bonnaud B, Collin V, van Belkum A, et al. Comparison of two approaches for the classification of 165 rRNA gene sequences. J Med Microbiol. 2014;63(Pt 10):1311-5.

29. Sutrave S, Kikhney J, Schmidt J, Petrich A, Wiessner A, Kursawe L, et al. Effect of daptomycin and vancomycin on Staphylococcus epidermidis biofilms: an in vitro assessment using fluorescence in situ hybridization. PLOS ONE. 2019;14(8):e0221786.

30. Poulsen LKBG, Stahl DA. Use of rRNA fluorescence in situ hybridization for measuring the activity of single cells in young and established biofilms. Appl Environ Microbiol. 1993;59(5):1354-60.

31. Stewart PS, Zhang T, Xu R, Pitts B, Walters MC, Roe F, et al. Reaction-diffusion theory explains hypoxia and heterogeneous growth within microbial biofilms associated with chronic infections. NPJ Biofilms Microbiomes. 2016;2:16012

32. Kerkhof LWB. Comparison of nucleic acid hybridization and fluorometry for measurement of the relationship between RNA/DNA ratio and growth rate in a marine bacterium. Appl Environ Microbiol. 1993;59(5):1303-9.

33. Zimmerli W, Trampuz A, Ochsner PE. Prosthetic-joint infections. N Engl J Med. 2004:351(16):1645-54. 
34. Waldmann I, Schmid T, Prinz J, Muhleisen B, Zbinden R, Imhof L et al. Photodynamic therapy improves skin antisepsis as a prevention strategy in arthroplasty procedures: a pilot study. Photodiagnosis Photodyn Ther. 2020:101941.

35. Blonna D, Allizond V, Bellato E, Banche G, Cuffini AM, Castoldi F, et al. Single versus double skin preparation for infection prevention in proximal humeral fracture surgery. Biomed Res Int. 2018;2018:8509527.

36. Scheer VM, Bergman Jungestrom M, Lerm M, Serrander L, Kalen A. Topical benzoyl peroxide application on the shoulder reduces Propionibacterium acnes: a randomized study. J Shoulder Elbow Surg. 2018;27(6):957-61.

37. Heckmann N, Sivasundaram L, Heidari KS, Weber AE, Mayer EN, Omid R, et al. Propionibacterium acnes persists despite various skin preparation techniques. Arthroscopy. 2018;34(6):1786-9.

38. Ulmer M, Lademann J, Patzelt A, Knorr F, Kramer A, Koburger T, et al. New strategies for preoperative skin antisepsis. Skin Pharmacol Physiol. 2014;27(6):283-92.

39. Daeschlein G, Napp M, Layer F, von Podewils S, Haase H, Spitzmueller $\mathrm{R}$, et al. Antimicrobial efficacy of preoperative skin antisepsis and clonal relationship to postantiseptic skin-and-wound flora in patients undergoing clean orthopedic surgery. Eur J Clin Microbiol Infect Dis. 2015;34(11):2265-73.

40. Bumb SS, Bhaskar DJ, Agali CR, Punia H, Gupta V, Singh V, et al. Assessment of photodynamic therapy (PDT) in disinfection of deeper dentinal tubules in a root canal system: an in vitro study. J Clin Diagn Res. 2014;8(11):67-71.

41. Tennert C, Feldmann K, Haamann E, Al-Ahmad A, Follo M, Wrbas KT, et al. Effect of photodynamic therapy (PDT) on Enterococcus faecalis biofilm in experimental primary and secondary endodontic infections. BMC Oral Health. 2014;14:132
42. Nakatsuji T, Chiang HI, Jiang SB, Nagarajan H, Zengler K, Gallo RL. The microbiome extends to subepidermal compartments of normal skin. Nat Commun. 2013:4:1431

43. Lee MJ, Pottinger PS, Butler-Wu S, Bumgarner RE, Russ SM, Matsen FA 3rd. Propionibacterium persists in the skin despite standard surgical preparation. J Bone Joint Surg Am. 2014;96(17):1447-50.

44. Matsen FA 3rd, Russ SM, Bertelsen A, Butler-Wu S, Pottinger PS. Propionibacterium can be isolated from deep cultures obtained at primary arthroplasty despite intravenous antimicrobial prophylaxis. J Shoulder Elbow Surg. 2015;24(6):844-7.

45. K. N, Fukushima H, Yukawa T, Nakaminami H, Fujii T, Noguchi. Propionibacterium acnes has low susceptibility to chlorhexidine digluconate. Surg Infect. 2018;19(3).

46. Phadnis J, Gordon D, Krishnan J, Bain Gl. Frequent isolation of Propionibacterium acnes from the shoulder dermis despite skin preparation and prophylactic antibiotics. J Shoulder Elbow Surg. 2016;25(2):304-10.

47. Cavanagh JP, Wolden R, Heise P, Esaiassen E, Klingenberg C, Aarag Fredheim EG. Antimicrobial susceptibility and body site distribution of community isolates of coagulase-negative staphylococci. APMIS. 2016;124(11):973-8.

48. Amann RI, Binder BJ, Olson RJ, Chisholm SW, Devereux R, Stahl DA. Combination of $16 \mathrm{~S}$ rRNA-targeted oligonucleotide probes with flow cytometry for analyzing mixed microbial populations. Appl Environ Microbiol. 1990;56(6):1919-25.

\section{Publisher's Note}

Springer Nature remains neutral with regard to jurisdictional claims in published maps and institutional affiliations.
Ready to submit your research? Choose BMC and benefit from:

- fast, convenient online submission

- thorough peer review by experienced researchers in your field

- rapid publication on acceptance

- support for research data, including large and complex data types

- gold Open Access which fosters wider collaboration and increased citations

- maximum visibility for your research: over $100 \mathrm{M}$ website views per year

At BMC, research is always in progress.

Learn more biomedcentral.com/submissions 